\title{
PLANEJAMENTO E CONTROLE DOS CUSTOS DA QUALIDADE: UMA INVESTIGAÇÃO DA PRÁTICA EMPRESARIAL*
}

\author{
PLANNING AND CONTROLLING OF QUALITY COSTS: \\ AN INVESTIGATION ON MANAGERIAL PRACTICE
}

\author{
MARCOS ANTONIO DE SOUZA \\ Professor Doutor do Centro de Ciências \\ Econômicas da \\ Universidade Vale do Rio dos Sinos - RS \\ E-mail: marcosas@unisinos.br
}

\author{
ELISANDRA COLLAZIOL \\ Professora Mestre do Programa de Educação \\ Continuada da \\ Universidade Vale do Rio dos Sinos - RS \\ E-mail: pesquisa_collaziol@terra.com.br
}

\section{RESUMO}

Este artigo tem como objetivo proceder a uma investigação da prática empresarial sobre o planejamento e controle dos custos da qualidade. Nesse sentido, contribui por oportunizar uma discussão atual sobre os procedimentos adotados pelas empresas, tanto no contexto da edição da norma NBR ISO 9004:2000, por meio da qual se passou a ter, pela primeira vez, uma explícita manifestação legal a respeito, como daqueles procedimentos recomendados pela literatura. $O$ estudo empírico contou com a participação de 53 empresas de médio e grande portes, certificadas e integrantes do cadastro da Fundação para o Prêmio Nacional da Qualidade (FPNQ), sendo 32 nacionais e 21 estrangeiras. Para tanto, utilizou-se de questionário encaminhado ao responsável pela área de gestão da qualidade. O estudo conduziu à conclusão de que as empresas permanecem não dedicando ao planejamento $e$ controle dos custos da qualidade a mesma atenção que dedicam à formalização do processo com vistas a obter a certificação do sistema de gestão da qualidade. Constatou-se a continuidade de baixa aplicação de procedimentos direcionados à classificação e mensuração dos custos da qualidade, inclusive na elaboração de relatórios gerenciais específicos e nas atividades de orçamento e medição do retorno dos investimentos em qualidade. Também ficou evidenciado que a baixa utilização é mais acentuada nas empresas nacionais.

Palavras-chave: Gestão do sistema da qualidade; Custo da qualidade; Mensuração dos custos da qualidade.

\section{ABSTRACT}

The objective of this article is to investigate the companies' practices regarding planning and controlling of quality costs. The study discusses current procedures adopted by the corporations according to the edition of the NBR ISO 9004:2000, which, for the first time, showed a legal recommendation about treatment of quality cost in line with the procedures recommended by the academic literature. The empiric research was developed based on 53 medium and large companies certified by ISO criteria, all of them associated to the Fundação para o Prêmio Nacional da Qualidade (FPNQ - Foundation For the National Prize on Quality ), a Brazilian association created to promote and improve quality system benefits. Of these 53 organizations, 32 are domestic companies and 31are Brazilian subsidiaries of multinational enterprises. To reach the goal of this research a questionnaire was sent to quality department managers. The research concluded that the organizations have not payed enough attention to the planning and controlling of quality costs in the same level that they have devoted to formalize the operational process to get the ISO certificate. The results of the research indicate that the companies have used few and superficial procedures to classify and measure quality costs as well as budgeting and evaluating the return of investment on quality and related management information reports. It was also observed that the poorer practices are more noticed in Brazilian domestic companies.

Keywords: Management of quality system; Quality Cost; Measuring quality cost.

Recebido em 03.01.2006 • Aceito em 18.05.2006 • 2 $2^{\mathrm{a}}$ versão aceita em 30.06.2006

* Artigo originalmente apresentado no XXIX EnANPAD, Brasília-DF, setembro/2005. 


\section{INTRODUÇÃO}

O crescimento das transações em negócios internacionais durante as décadas recentes é um fenômeno que virtualmente tem conectado todos os países, cada vez mais, tornando-os dependentes do comércio e dos investimentos internacionais. O aumento do comércio internacional de produtos, serviços e tecnologia, assim como o aumento de investimentos estrangeiros, são as forças direcionadoras da internacionalização dos negócios.

No contexto da globalização de mercados e da conseqüente expansão dos negócios internacionais, há um desejo comum das empresas, independentemente de suas origens: o de alavancar operações e resultados. A relativa eliminação das fronteiras $e$ barreiras na esfera de atuação das empresas, aliada ao expressivo avanço nas tecnologias de produção e comunicação, tem resultado na existência de um mercado cada vez mais competitivo e exigente.

É nesse contexto que se manifesta Mondem (1999, p.19), afirmando que:

Hoje em dia, a competição entre as empresas transcende fronteiras, uma vez que elas competem nos mercados internacionais. Em resumo, toda essa competição tem um objetivo comum: oferecer produtos com qualidade que agradem aos consumidores a preços acessíveis. Esse tipo de competição está se tornando cada vez mais árduo na arena do mercado global.

Corroborando o entendimento de Mondem, Nakagawa (1991) destaca que, nas duas últimas décadas do século passado, o recrudescimento da competição global tem sido de tal ordem que as empresas vêm sendo compelidas a se comprometerem seriamente com a chamada filosofia de excelência empresarial.

A questão da excelência destacada por Nakagawa também tem sido reconhecida por outros pesquisadores. Hansen e Mowen (2001), por exemplo, destacam que a melhoria contínua e a eliminação de desperdício são os dois princípios básicos que governam um estado de excelência na manufatura. Tais autores complementam afirmando que a excelência na manufatura é a chave para a sobrevivência no ambiente atual de competitividade de classe mundial.

Dentre os vários fatores que caracterizam o estágio de excelência destacado por Nakagawa e Hansen e Mowen, e ainda no âmbito do acirramento da competição global, Fawcett, Calantone e Roath (2000) destacam que custo e qualidade são os seus focos primários, por serem eles demandados por consumidores globais, e correspondem aos fundamentos sobre os quais outras capacidades compe- titivas são construídas. Tal reconhecimento decorre da constatação de que os clientes, cada vez mais, anseiam e privilegiam produtos revestidos com a qualidade por eles desejada e ao menor preço.

Porter (1990) trata desses atributos no contexto do estabelecimento de estratégias empresariais que objetivam a criação de uma vantagem competitiva sustentável.

Para assegurar o atendimento ao requisito da qualidade, as empresas têm se dedicado à certificação do sistema por meio do atendimento às determinações das normas ISO. Quanto aos custos decorrentes, sejam eles originados pelos gastos realizados para a obtenção da qualidade, ou pela falta dela, a preocupação deve ser a mesma.

Tem sido reconhecido pela literatura contábil que a variável 'custos', em seu contexto geral, influencia de forma determinante na dimensão de resultados. Portanto, a sua gestão é um pré-requisito para a eficácia organizacional, visto possibilitar a obtenção de uma economia de custos eficaz, com benefícios para a empresa e seus clientes. Obviamente isso também é aplicável com relação aos custos da qualidade em particular, objeto deste estudo.

Tem-se, então, que, ao tratar da prática empresarial quanto ao planejamento e controle dos custos da qualidade, este estudo está diretamente relacionado à discussão de aspectos que envolvem e sustentam a continuidade das organizações.

\section{OBJETIVOS E CONTRIBUIÇÃO DA PESQUISA}

O objetivo central da pesquisa é o de investigar o nível de aderência das empresas pesquisadas no que se refere à adoção efetiva das práticas de gestão de custos tanto sob o foco dos desenvolvimentos teóricos verificados na literatura quanto ao previsto na norma NBR ISO 9004:2000.

A motivação para a execução desta pesquisa decorre da sugestão de Moori e Silva (2001) para novos estudos sobre a matéria, tendo em vista que, na opinião deles, com a edição da série 2000 das normas ISO a mensuração de custos da qualidade passou a ser um item obrigatório para fins de certificação.

Mesmo sendo tal afirmativa passível de discussão, visto também ser possível a interpretação de que na realidade NBR ISO 9004:2000 indica uma recomendação de adoção, a contribuição deste estudo está em oportunizar uma discussão atual sobre os procedimentos adotados pelas empresas. Seja obrigatória, ou não, a realidade é que com a edição da NBR ISO 9004:2000 passou-se a ter, pela primeira vez, uma explícita manifestação legal a respeito. 
Entende-se, portanto, que após cinco anos de vigência da norma é oportuno diagnosticar o nível de reconhecimento que as empresas dedicam à necessidade de planejamento e controle dos custos da qualidade, procedimento esse já há muito tempo referendado pelos diversos pesquisadores consultados.

A justificativa deste estudo suporta-se na interpretação dada por ludícibus (1996, p. 31). O autor, ao fazer uma análise sucinta da Gestão Estratégica de Custos e de sua ligação com a Contabilidade Gerencial e com a Teoria da Contabilidade, destaca que:

Em primeiro lugar, é importante deixar claro que o que mais importa, na realidade, é a qualidade da prática contábil. A doutrina tem sua grande importância, é bem verdade, quando consegue projetar estruturas conceituais que se antecipam à prática (mas que devem ser validadas pelos experimentos reais).

Outra motivação para a realização deste estudo é a constatação da necessidade de pesquisas direcionadas a investigar a adoção de práticas de mensuração e registro dos custos da qualidade com base em uma amostra mais significativa de empresas. De fato, há uma preponderância de estudos que têm pautado o seu desenvolvimento na estratégia metodológica de estudos de casos ou na ênfase conceitual sobre a validade e utilidade da mensuração e controle dos custos da qualidade como instrumento de gestão.

Como exemplo de tal constatação, têm-se, entre outros, os estudos de Carvalho et al. (2000), Lima e Martins (2001), Nascimento (2003) e Quesado e Da Costa (2005).

\section{REFERENCIAL TEÓRICO}

\subsection{Iniciativas para os Sistemas da Qualidade}

Apesar do grande destaque dado nas últimas décadas à implantação de sistemas da qualidade, atingindo ela o status de alta relevância entre aqueles elementos que constituem a gestão estratégica empresarial, deve ser reconhecido que a questão da qualidade já vem sendo discutida com muito mais antecedência.

Robles Jr. (2003, p.21) destaca que "O conceito de Total Quality Control foi introduzido por Armand V. Feigenbaum, através de um artigo publicado em 1957 na revista Industrial Quality Control; em seguida, em 1961 publicou um livro, intitulado Total Quality Control: engeneering and management”. Wilbur (2002, p.75), também, manifesta-se no mesmo sentido, ao afirmar que "Os princípios que fundamentam os atuais proce- dimentos dos sistemas da qualidade estão largamente baseados nos desenvolvimentos iniciados há mais de 50 anos por alguns poucos pesquisadores, como, por exemplo, W. Edwards Deming".

Apesar do destaque que é dado ao fenômeno da globalização como o principal indutor para as iniciativas quanto aos sistemas da qualidade, tendo em vista as exigências impostas por um mercado caracterizado por uma concorrência mais acirrada, um evento mais pontual, e parte integrante de tal globalização, também tem merecido destaque na literatura pertinente. Trata-se da agressiva iniciativa das empresas japonesas que incorporaram a questão da qualidade como uma estratégia diferenciada para a época.

De fato, nos anos 1970 e 1980, os japoneses desencadearam uma revolução global na eficácia operacional, introduzindo práticas pioneiras, como a gestão da qualidade total e melhoria contínua. Em conseqüência, os fabricantes japoneses desfrutaram, durante muitos anos, de substanciais vantagens de custo e qualidade.

Tal vantagem competitiva japonesa, em conseqüência, passou a ser uma ameaça à continuidade das demais empresas concorrentes. A partir de tal constatação, o tema qualidade passou, de forma mais efetiva, a fazer parte da agenda de todas as empresas preocupadas em assegurar a sua continuidade no cumprimento de sua missão.

Fawcett, Calantone e Roath (2000, p. 475) sustentam tal constatação, ao afirmarem que "Qualidade emergiu como uma vital prioridade competitiva em resposta à invasão japonesa ocorrida no final dos anos de 1970 e início dos anos de 1980".

Tal reconhecimento também pode ser encontrado em Sakurai (1997, p. 130) quando esse afirma que "Made in Japan, anteriormente objeto de desdém, é atualmente uma marca de distinção. Os japoneses são os líderes reconhecidos da moderna revolução mundial da qualidade, [...]".

A influência da iniciativa japonesa, também, é destacada por Robles Jr. (2003). Cita o autor que Deming, o qual alcançou notória proeminência em virtude de sua atuação no Japão, na década de 1950, profetizou que em breve o país conquistaria o mercado mundial, o que foi plenamente confirmado.

\subsection{Formalização dos Sistemas da Qualidade}

Uma decorrência natural da internacionalização da economia, provocada pelo fenômeno da globalização, e além daquelas já destacadas na introdução deste estudo, foi a preocupação em harmonizar, em nível mundial, alguns procedimentos no âmbito das empresas. 
Isso tem sido verificado em diversas áreas, como, por exemplo, na harmonização das práticas contábeis, conforme destacado por Castro (2001) e CFC (2005). No âmbito dos procedimentos direcionados a assegurar um padrão desejado de qualidade isso não tem sido diferente. A criação da International Organization for Standardization (ISO) ratifica tal entendimento.

Oliveira e Melhado (2004) destacam que a ISO é uma entidade não governamental, criada em 1947, com sede em Genebra, Suíça. Ela tem como objetivo promover o desenvolvimento da normalização e atividades relacionadas com a intenção de facilitar o intercâmbio internacional de bens e desenvolver a cooperação nas esferas intelectual, científica, tecnológica e de atividade econômica. Como decorrência tem-se o surgimento das Normas ISO, as quais representam um padrão mundial de referência em relação à gestão da qualidade.

Os membros que compõem a ISO são os representantes das entidades máximas de normalização nos respectivos países associados, como o Instituto Nacional de Metrologia (INMETRO), no caso do Brasil. Tais representantes, por meio da atuação dos respectivos comitês técnicos - no Brasil a Associação Brasileira de Normas Técnicas (ABNT), são responsáveis pelos trabalhos técnicos necessários à estrutura, emissão e atualização das referidas normas, as quais devem ser observadas pelas entidades credenciadas para os trabalhos de certificação.

A formalização dos sistemas da qualidade ocorre sob a observação de três normas principais, revisadas em 2000, conforme Quadro 1:

\begin{tabular}{|c|l|l|}
\hline Norma & \multicolumn{1}{|c|}{ Denominação } & \multicolumn{1}{c|}{ Escopo } \\
\hline ISO 9000 & $\begin{array}{l}\text { Sistema de Gestão da Qualidade: fundamentos e } \\
\text { vocabulário }\end{array}$ & $\begin{array}{l}\text { Descreve os fundamentos de sistemas de gestão da qua- } \\
\text { lidade e estabelece a terminologia para esses sistemas. }\end{array}$ \\
\hline ISO 9001 & Sistema de Gestão da Qualidade: requisitos & $\begin{array}{l}\text { Especifica requisitos para um sistema de gestão da } \\
\text { qualidade - no qual uma organização precisa demonstrar } \\
\text { sua capacidade para fornecer produtos que atendam aos } \\
\text { requisitos do cliente e aos regularmente aplicáveis - e } \\
\text { objetiva aumentar a satisfação dos clientes. }\end{array}$ \\
\hline ISO 9004 & $\begin{array}{l}\text { Sistema de Gestão da Qualidade: diretrizes para } \\
\text { melhoria de desempenho }\end{array}$ & $\begin{array}{l}\text { Fornece diretrizes que consideram tanto a eficácia } \\
\text { como a eficiência do sistema de gestão da qualidade. } \\
\text { O objetivo dessa norma é melhorar o desempenho da } \\
\text { organização e a satisfação de clientes e de outras partes } \\
\text { interessadas. }\end{array}$ \\
\hline
\end{tabular}

Fonte: Adaptado de Oliveira e Melhado (2004, p. 68).

\section{Quadro 1 - Normas Série ISO 9000}

A versão 2000 das normas ISO, uma atualização da versão editada em 1994, surgiu em decorrência das críticas de que a versão anterior era "pesadona, confusa e com forte viés de manufatura" (OLIVEIRA e MELHADO, 2004, p. 66). O objetivo passou a ser a edição de uma norma voltada para os processos da organização, para seus clientes e para a melhoria contínua do desempenho do sistema da gestão da qualidade.

Esse entendimento é colocado de forma explícita pela norma NBR ISO 9001:2000, em seu tópico 0.2 - Abordagem de Processo, quando destaca que "Esta norma promove a adoção de uma abordagem de processo para o desenvolvimento, implementação e melhoria da eficácia de um sistema de gestão da qualidade para aumentar a satisfação do cliente pelo atendimento aos requisitos do cliente."

Oliveira e Melhado (2004), ao enfatizarem que a preocupação com as especificações só pode ser tratada após cuidadosa identificação das necessidades dos usuários, acrescentam que "se assim não fosse, a excelência do controle de processo teria pouca vantagem, pois ficaria facilmente desviada do seu foco: necessidades dos clientes" (p. 14).

Diversos são os pesquisadores que contribuíram para o surgimento e evolução dos sistemas da qualidade.

Sacco Galloro e Stephani (1995) desenvolveram amplo estudo envolvendo os custos da qualidade e da não-qualidade. Além da definição e classificação desses custos, os autores avançaram em outros tópicos relacionados, tais como: o ponto ótimo do custo da qualidade, o custo do ciclo de vida do produto e as medidas dos resultados dos investimentos em qualidade.

De Forma mais específica e analítica, Sacco Galloro e Stephani, utilizando-se do método de Custeio Baseado em Atividades (ABC), apresentam 
modelos de relatórios dos custos da qualidade no âmbito das atividades que caracterizam os custos de controle (prevenção e avaliação) e os custos das falhas (internas e externas). Tais relatórios visam possibilitar a análise, entendimento e controle dos custos envolvidos, base para a tomada de decisões que objetivam assegurar o alcance da eficácia do sistema como um todo.

Robles Jr. (2003), ao citar que as empresas têm-se preocupado com a qualidade do produto desde os primórdios da era industrial, vai ao encontro da abordagem dada pela mais recente versão das normas ISO, ao afirmar que o que pode ser considerado mais ou menos recente é a preocupação com o processo, o que redunda nos conceitos da Total Quality Control (TQC). Nesse processo de evolução, Robles Jr. (2003) destaca as contribuições de Crosby, Deming, Juran, Feigenbaum, Shewhart e Taguchi, entre outros.

As contribuições dos pesquisadores citados por Robles Jr., de forma explícita ou implícita encontram-se contempladas na formalização dos sistemas da qualidade. Um exemplo é a sugestão para a adoção da metodologia PDCA, desenvolvida inicialmente por Shewhart na década de 1930, e posteriormente adotada por Deming (ANDRADE, 2003), constante em nota ao tópico 02 - Abordagem de processo, da norma NBR ISO 9001:2000:

NOTA - Adicionalmente, pode ser aplicada a metodologia conhecida como Plan-Do-CheckAct (PDCA) para todos os processos. O modelo PDCA pode ser descrito resumidamente como segue: Plan (planejar): estabelecer os objetivos e processos necessários para fornecer resultados de acordo com os requisitos do cliente e políticas da organização; Do (fazer): implementar os processos; Check (checar): monitorar e medir processos e produtos em relação às políticas, aos objetivos e aos requisitos para o produto e relatar resultados; Act (agir): executar ações para promover continuamente a melhoria do desempenho do processo.

\subsection{Custos da Qualidade}

A gestão dos custos da qualidade tem sido, há algumas décadas, incluída na agenda do que se convencionou denominar gestão estratégica de custos. Isso é uma decorrência natural do fato de que a gestão da qualidade total também passou a integrar as estratégias empresariais que objetivam assegurar o estabelecimento de vantagem competitiva ante os seus concorrentes.

No âmbito da gestão estratégica, Wright, Kroll e Parnell (2000) fazem ampla abordagem a respeito, destacando a dedicação à qualidade, à inovação de processo, à inovação de produto e à alavancagem por meio da perícia e da imagem organizacionais, classificando-os como modos pelos quais as organizações podem diferenciar seus produtos e serviços. Já sob a perspectiva da gestão estratégica de custos, Shank e Govindarajan (1997) destacam a importância da medição e análise de custos da qualidade no contexto dos fatores direcionadores dos custos das atividades empresariais.

Apesar de Deming entender que a análise dos custos da qualidade é pura perda de tempo, já que para ele os benefícios de um efetivo programa de qualidade total são tão evidentes que as empresas fariam melhor se dedicassem tempo e dinheiro no seu aperfeiçoamento, conforme destacam Shank e Govindarajan (1997) e Robles Jr (2003), diversos outros pesquisadores da área da qualidade total tem posicionamento contrário. Entre esses últimos encontram-se, por exemplo, Juran e Gryna (1991), Crosby (1994) e Feigenbaum (1994). Entendem eles que a coleta e a análise periódicas dos custos da qualidade monitoram a eficácia do sistema da qualidade quanto a custos, ao mesmo tempo em que direcionam iniciativas para o seu aperfeiçoamento.

Nas obras relacionadas à gestão de custos e contabilidade gerencial também é identificado um entendimento geral favorável de diversos pesquisadores quanto à necessidade e benefícios decorrentes do controle dos custos da qualidade. Dentre tais pesquisadores podem-se citar: Horngren, Foster e Datar (2000), Atkinson et al. (2000), Maher (2001), Rust, Zahorik e Keiningham (1994). De fato, para tais autores a gestão dos custos da qualidade é um pré-requisito para o alcance da eficácia dos sistemas da qualidade.

A utilização da mensuração e gestão dos custos da qualidade também estão presentes nas normas ISO. Elas são encontradas de forma mais específica na NBR ISO 9004:2000:

a) no tópico 8.2.1.3 - Auditoria Interna expõe que: "Convém que a Alta Direção assegure o estabelecimento de um processo eficaz e eficiente de auditorias internas para avaliar os pontos fortes e os pontos fracos do sistema de gestão da qualidade".

b) na sequência, expõe: "Exemplos de assuntos a serem considerados pelas auditorias internas incluem: [...] análise de dados de custos da qualidade [...]."

c) no tópico 8.2.1.4 - Medições Financeiras expõe que: "Convém que a direção considere a conversão de dados de processo em informações financeiras para fornecer medidas comparáveis ao longo dos pro- 
cessos e para facilitar melhorias da eficácia e eficiência da organização. Exemplos de medidas financeiras incluem: análise dos custos de prevenção e avaliação; análise dos custos de não conformidade; análise dos custos de falhas internas e externas, $e$ análise dos custos do ciclo de vida."

Apesar da exposição explícita quanto a procedimentos para mensuração dos custos da qualidade, deve ser lembrado que a NBR ISO 9004:2000, de acordo com Oliveira e Melhado (2004, p. 64), "é uma norma que estabelece diretrizes e descreve um conjunto básico de elementos pelos quais o sistema pode ser desenvolvido. Sendo assim, o usuário dessa norma pode selecionar os elementos do sistema da qualidade adequados à sua realidade empresarial".

Sendo assim, a utilização dos termos 'convém' e 'pode ser', pela referida norma, aliado à interpretação de Oliveira e Melhado (2004), conduz à conclusão de que a adoção de procedimentos direcionados ao controle dos custos da qualidade não é um item obrigatório para a certificação do sistema da qualidade. Em sendo assim, trata-se mais de um procedimento sugerido e considerado como recomendável e oportuno.

Não obstante tal interpretação, Moori e Silva (2001) entendem que a obrigatoriedade está caracterizada e passou a existir a partir da edição da nova versão das normas ISO, no ano de 2000.

Independentemente da obrigatoriedade ou não de adoção de tais procedimentos, no âmbito das normas ISO, para fins deste estudo prevalece a premissa de que a eficácia do sistema de gestão da qualidade não pode prescindir de um adequado sistema de planejamento e controle dos custos relacionados. Assume-se, portanto, o mesmo entendimento de pré-requisito defendido pelos diversos autores pesquisados.

\subsection{Mensuração e Avaliação dos Custos da Qualidade}

A forma de mensurar e avaliar os custos da qualidade depende muito da classificação e estrutura que se pretende adotar em relação a eles.

Juran e Gryna (1991, p. 86) afirmam que:

o termo custos da qualidade assumiu significados diferentes para pessoas diferentes. Alguns os compararam aos custos para se atingir a qualidade. Outros equipararam o termo aos custos para o funcionamento do Departamento de Qualidade. A interpretação a que chegaram os espe- cialistas em qualidade foi equiparar os 'custos da qualidade' com o custo da má qualidade (principalmente os custos para se encontrar e corrigir o trabalho defeituoso).

Para os fins deste estudo, adotar-se-á a classificação mais freqüentemente encontrada nas obras relacionadas a custos da qualidade. Trata-se da classificação desenvolvida por Feigenbaum (1994), também encontrada, entre outras, na obra de Crosby (1994), Juran e Gryna (1991) e Rust, Zahorik e Keiningham (1994) ${ }^{1}$.

Deve-se enfatizar que a classificação adotada por Feigenbaum, também, foi incorporada pelas práticas recomendadas pela norma NBR ISO 9004:2000 em seu tópico "8.2.1.4 - Medições Financeiras", conforme destacado no tópico anterior deste estudo.

A Figura 1, a seguir, apresentada sumariza a classificação idealizada por Feigenbaum:

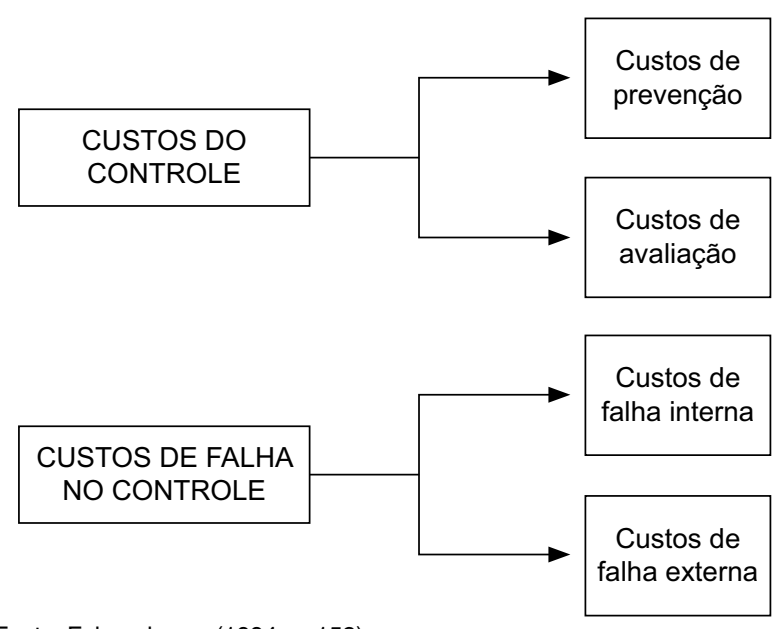

Fonte: Feigembaum (1994, p. 152)

Figura 1: Classificação dos custos da qualidade

Para Feigenbaum (1994) os custos de controle são medidos em duas partes: [1] Custos de Prevenção, que evitam ocorrência de defeitos e não-conformidades e compreendem gastos com a qualidade para, antes de tudo, evitar produtos insatisfatórios; incluem, entre outros, os custos de engenharia da qualidade e treinamento de funcionários para a qualidade; [2] Custos de Avaliação, que abrangem custos de manutenção dos níveis da qualidade da companhia através de análises formais da qualidade do produto; envolve custo como inspeção, confirmação externa, auditorias da qualidade e outros gastos similares. 
Já os custos provenientes de falha no controle, causados por materiais e produtos que não atendem às especificações, são igualmente medidos em duas partes: [1] Custos de Falha Interna, que incluem custos da qualidade insatisfatória dentro da companhia, tais como material refugado, danificado e retrabalhado; [2] Custos da Falha Externa, que abrangem custos da qualidade insatisfatória situados na parte externa da companhia, tais como falhas provenientes do desempenho do produto e reclamações dos clientes.

$\mathrm{Da}$ configuração dada por Feigenbaum podese inferir que em uma empresa ideal a plena eficácia dos investimentos realizados no primeiro grupo fariam com que os valores do segundo grupo tenderiam a zero.

Ainda no entendimento de Feigenbaum, os custos da qualidade constituem as bases por meio das quais investimentos em programas da qualidade podem ser avaliados em termos de melhoramento de custos, aumento da lucratividade e outros benefícios originados por esses programas. Em essência, os custos da qualidade constituem a base fundamental para a economia dos sistemas da qualidade.

A participação da contabilidade no processo de registro dos custos da qualidade é enfaticamente recomendada por Crosby (1994, p. 133), ao afirmar que "Todos os cálculos devem ser feitos pelo departamento de contabilidade, o que garante a integridade da operação". A participação da controladoria também mereceu destaque de Crosby. Ao tratar da avaliação do custo da qualidade o autor destaca que (p. 145) "é provável que as estimativas iniciais sejam indecisas (embora baixas), de modo que é preciso obter cifras mais acuradas. Quem deve fornecê-las é o controller (...) fazer com que o controller estabeleça o custo da qualidade afasta qualquer suspeição do cálculo".

Diversos estudos têm sido publicados enfatizando a expressividade dos custos provocados pela falta de qualidade de produtos e serviços.

Garrison e Noreen (2001, p. 627) enfatizam que "Estudos mostram que os custos da qualidade das companhias americanas variam de 10 a $20 \%$ das vendas totais, enquanto os especialistas indicam que esses custos deveriam situar-se na faixa de 2 a $4 \% "$.

Dentre outros estudos, destaca-se o apresentado por Imberman (2001), originado da pesquisa realizada pela Dun \& Bradstreet junto a empresas norte-americanas de diversos segmentos industriais, divulgado em fevereiro de 2001, evidenciando um custo provocado pela falta da qualidade equivalente a $7,2 \%$, em média, contra um lucro líquido médio da ordem de 3,2\%. Portanto, significativos.

Partindo-se da premissa de que as empresas desenvolvem suas atividades em um mercado caracterizado por acirrada concorrência, conforme descrito na Introdução deste estudo, é lógico inferir que o repasse de tais custos nos preços fica prejudicado e, por conseqüência, reduz o potencial de lucro passível de ser alcançado. Portanto, a busca da eficácia empresarial passa, necessariamente, pelo planejamento e controle desses custos.

\section{CLASSIFICAÇÃO DA PESQUISA, CARACTERIŽAÇÃO DA AMOSTRA, COLETA E TRATAMENTO DE DADOS}

Com base no entendimento dado por Gil (1999), esta pesquisa é classificada como descritiva e exploratória. Descritiva porque busca identificar as características de uma população quanto à ocorrência de um determinado fenômeno. E exploratória, porque oportuniza a discussão desse fenômeno em uma forma ainda não tão abordada pela literatura. Gil (1999, p. 44) enfatiza que "As pesquisas descritivas são, juntamente com as exploratórias, as que habitualmente realizam os pesquisadores sociais preocupados com a atuação prática".

A amostra utilizada na pesquisa de campo é composta por empresas certificadas pela norma ISO 9001:2000 e integrantes do cadastro da Fundação para o Prêmio Nacional da Qualidade (FPNQ) ${ }^{2}$, base agosto de 2004, época da coleta de dados. Do cadastro geral da FPNQ, entidade de referência e reconhecimento nacional, constam 154 empresas. Foram selecionadas 98 empresas, classificadas como de porte médio ou grande de acordo com o faturamento anual.

Mediante prévio contato telefônico, enviou-se às empresas selecionadas um questionário formado por 16 perguntas fechadas. Do total de questionários enviados foram respondidos 63 (64\% do total). Desses, 10 (16\% dos recebidos) foram excluídos por não confirmarem a certificação ou por respostas incompletas. Ao final trabalhou-se com 53 questionários, correspondendo a $54 \%$ do total enviado. Tais questionários foram endereçados ao responsável pela gestão do sistema da qualidade.

\footnotetext{
2 A FPNQ tem como missão disseminar os fundamentos da excelência em gestão para o aumento de competitividade das organizações e do Brasil. O foco na excelência em gestão evidencia que a FPNQ está voltada para uma atuação mais ampla que a qualidade de processos e produtos. Para tanto, estabeleceu diversos critérios (oito no total) representativos de tal excelência em gestão.
} 
O questionário foi estruturado em dois grupos. O primeiro destinou-se à identificação geral da empresa quanto ao porte e aos aspectos operacionais e estruturais da área responsável pelo sistema da qualidade; o segundo, à identificação dos procedimentos adotados no planejamento e controle dos custos da qualidade.

Metodologicamente, o questionário foi elaborado com base em Gil (1999, p. 129), para o qual "construir um questionário consiste basicamente em traduzir os objetivos da pesquisa em questões específicas". Antes da sua utilização definitiva e baseando-se em Lakatos e Marconi (1991), o questionário foi submetido a um pré-teste, aplicado a três respondentes com o perfil desejado pela pesquisa, cujas empresas não compuseram a amostra utilizada no estudo.

Quanto ao conteúdo, dados os objetivos da pesquisa, o questionário foi elaborado com base nos estudos de Crosby (1994), Feijenbaum (1994) e Tatikonda e Tatikonda (1996).

O conjunto dos segmentos de atuação das empresas que compõem a amostra apresentou grande variedade, envolvendo, entre outros: químico, petroquímico, siderúrgico, metalúrgico, eletroeletrônico, mineração, automotivo, geração e transmissão de energia elétrica, metal-mecânico, fumo, moveleiro e transporte aéreo.

Para descrever e sumarizar as características dos dados que pertencem ao conjunto da amostra utilizou-se da estatística descritiva, mediante a quantificação da freqüência e da participação relativa expressa em percentual.

Além dessa exposição quantitativa os dados foram submetidos a uma análise complementar e de natureza qualitativa.

\section{ANÁLISE E DISCUSSÃO DOS DADOS}

\subsection{Quanto à Origem, Porte das Empresas e Sistema da Qualidade}

Os dados da Tabela 1 evidenciam que da amostra total de 53 empresas, $32(60,4 \%)$ caracterizam-se como de controle acionário nacional, e 21 (39,6\%) de controle estrangeiro. Em ambos os grupos as empresas classificam-se como de grande porte, com mais de $70 \%$ delas apresentando faturamento anual superior a US\$ 100 milhões. Portanto, empresas de elevada representatividade econômica.

Tabela 1: Classificação das Empresas por Faixa de Faturamento

\begin{tabular}{l|c|c|c|c|c|c}
\hline \multirow{2}{*}{$\begin{array}{c}\text { Faturamento Anual } \\
\text { (US\$ Milhões) }\end{array}$} & \multicolumn{3}{|c|}{ Nacional } & \multicolumn{2}{c|}{ Estrangeiro } & \multicolumn{3}{c}{ Total } \\
\cline { 2 - 7 } & Freqüência & $\%$ & Freqüência & $\%$ & Freqüência & \% \\
\hline Até 100 & 9 & 28,1 & 6 & 28,6 & 15 & 28,3 \\
\hline De 101 a 300 & 10 & 31,3 & 5 & 23,8 & 15 & 28,3 \\
\hline Acima de 300 & 13 & 40,6 & 10 & 47,6 & 23 & 43,4 \\
\hline Total & 32 & 100 & 21 & 100 & 53 & 100 \\
\hline
\end{tabular}

Quanto à área responsável pela gestão do sistema da qualidade, os dados das Tabelas 2 e 3 demonstram que as empresas estão adequadamente estruturadas. Todas elas contam com uma entidade organizacional especificamente criada para a gestão do sistema. Apesar da diferença verificada entre as empresas, quanto ao nível hierárquico do responsá- vel principal pela área, constata-se a predominância dos níveis de diretor e gerente, acima de $79 \%$ ( $84,4 \%$ nas nacionais e $71,5 \%$ nas estrangeiras). $\mathrm{Na}$ opção "Outros" prevalece o nível hierárquico de supervisor. Nota-se, portanto, aderência ao recomendado por vários pesquisadores, como, por exemplo, Deming (1990).

Tabela 2: Existência de Área Específica para Gestão do Sistema da Qualidade

\begin{tabular}{l|c|c|c|c|c|c|}
\multirow{2}{*}{ Alternativas } & \multicolumn{2}{|c|}{ Nacional } & \multicolumn{2}{c|}{ Estrangeiro } & \multicolumn{2}{c}{ Total } \\
\cline { 2 - 7 } & Freqüência & $\%$ & Freqüência & $\%$ & Freqüência & \% \\
\hline Existe & 32 & 100,0 & 21 & 100,0 & 53 & 100,0 \\
\hline Não Existe & 0 & 0 & 0 & 0 & 0 & 0 \\
\hline Total & 32 & 100,0 & 21 & 100,0 & 53 & 100,0 \\
\hline
\end{tabular}


Tabela 3: Nível Hierárquico do Principal Responsável pela Gestão da Qualidade

\begin{tabular}{l|c|c|c|c|c|c}
\multirow{2}{*}{ Nível Hierárquico } & \multicolumn{2}{|c|}{ Nacional } & \multicolumn{2}{c|}{ Estrangeiro } & \multicolumn{2}{c}{ Total } \\
\cline { 2 - 7 } & Freqüência & $\%$ & Freqüência & $\%$ & Freqüência & $\%$ \\
\hline Diretor & 7 & 21,9 & 9 & 42,9 & 16 & 30,2 \\
\hline Gerente & 20 & 62,5 & 6 & 28,6 & 26 & 49,1 \\
\hline Outros & 5 & 15,6 & 6 & 28,6 & 11 & 20,8 \\
\hline Total & 32 & 100,0 & 21 & 100,0 & 53 & 100,0 \\
\hline
\end{tabular}

Entre as ferramentas utilizadas na gestão da qualidade verifica-se uma consistência em relação aos instrumentos prescritos pela literatura pertinente e pela própria NBR ISO 9001:2000. Isso pode ser constatado pelos dados da Tabela 4, a qual evidencia que $100 \%$ das empresas nacionais e $90,5 \%$ das estrangeiras utilizam-se da ferramenta PDCA. A ado- ção do Seis Sigma, apesar de menos citado, também se apresenta de forma significativa. Na opção "Outros", constatou-se a predominância da prática do $5 \mathrm{~S}^{3}$. Quanto a essas ferramentas, as empresas acham-se em sintonia com os desenvolvimentos de Feigenbaum (1994) e Juran e Gryna (1991).

Tabela 4: Ferramentas de Gestão da Qualidade

\begin{tabular}{l|c|c|c|c|c|c}
\multirow{2}{*}{$\begin{array}{c}\text { Ferramentas } \\
\text { de Gestão }\end{array}$} & \multicolumn{2}{c|}{ Nacional } & \multicolumn{2}{c|}{ Estrangeiro } & \multicolumn{2}{c}{ Total } \\
\cline { 2 - 7 } & Freqüência & $\%$ & Freqüência & $\%$ & Freqüência & \% \\
\hline PDCA & 32 & 100,0 & 19 & 90,5 & 51 & 96,2 \\
\hline Seis Sigma & 10 & 31,3 & 10 & 47,6 & 20 & 37,7 \\
\hline Outros & 13 & 40,6 & 10 & 47,6 & 23 & 43,4 \\
\hline
\end{tabular}

A utilização de unidades de medidas não financeiras para análise de desempenho do sistema da qualidade também é uma prática acentuada nas empresas, procedimento consistente com a proposta de Ishikawa (1998). De fato, com exceção de 4 empresas nacionais $(12,5 \%$ do grupo e $7,5 \%$ do total da amostra), para todas as demais isso é uma realidade, inclusive com a maioria utilizando mais de uma unidade de medida.

Os dados da Tabela 5 mostram que as métricas Porcentagem de Defeitos da Produção e Retra- balhos têm praticamente o mesmo nível de aplicação nos dois grupos da amostra, correspondendo a $47,2 \%$ do total das empresas. A métrica Garantias Executadas é mais predominante nas empresas estrangeiras $(61,9 \%)$ do que nas nacionais $(34,4 \%)$. No total, não há diferença relevante em relação às duas outras unidades de medidas analisadas. $O$ indicador Perda por Milhão - PPM é o menos citado e aparece com mais predominância nas empresas estrangeiras $(28,6 \%$ contra $9,4 \%)$.

Tabela 5: Métricas Utilizadas para Mensuração da Falta de Qualidade

\begin{tabular}{l|c|c|c|c|c|c}
\multirow{2}{*}{ Métricas } & \multicolumn{3}{|c|}{ Nacional } & \multicolumn{2}{c|}{ Estrangeiro } & \multicolumn{2}{c}{ Total } \\
\cline { 2 - 7 } & Freqüência & $\%$ & Freqüência & $\%$ & Freqüência & $\%$ \\
\hline Perda por Milhão & 3 & 9,4 & 6 & 28,6 & 9 & 17,0 \\
\hline \% Defeitos da Produção & 15 & 46,9 & 10 & 47,6 & 25 & 47,2 \\
\hline Garantias Executadas & 11 & 34,4 & 13 & 61,9 & 24 & 45,3 \\
\hline
\end{tabular}

3 Conforme OSADA (1992) a prática dos 5S refere-se à preparação do ambiente físico e comportamental para o desenvolvimento da qualidade total. Abrange: Seleção, Ordenação, Limpeza, Bem-Estar e Disciplina. 
Continuação

\begin{tabular}{l|c|c|c|c|c|c}
\multirow{2}{*}{ Métricas } & \multicolumn{2}{c|}{ Nacional } & \multicolumn{2}{c|}{ Estrangeiro } & \multicolumn{2}{c}{ Total } \\
\cline { 2 - 7 } & Freqüência & $\%$ & Freqüência & $\%$ & Freqüência & $\%$ \\
\hline Retrabalhos & 15 & 46,9 & 10 & 47,6 & 25 & 47,2 \\
\hline Outros & 6 & 18,8 & 5 & 23,8 & 11 & 20,8 \\
\hline Não Utiliza & 4 & 12,5 & 0 & 0,0 & 4 & 7,5 \\
\hline
\end{tabular}

A adoção de um sistema de premiação financeira como fator motivacional e de recompensa por atingir metas de qualidade, enfatizado por Oakland (1994) e Hansen e Mowen (2001) como uma prática que potencializa a eficácia dos programas de qualidade, apresenta-se de forma mais significativa nas empresas estrangeiras $(61,9 \%)$ do que nas nacionais $(46,9 \%)$. (Tabela 6).

Tabela 6: Existência de Premiação Financeira a Funcionários por Atingimento de Metas

\begin{tabular}{l|c|c|c|c|c|c}
\multirow{2}{*}{ Alternativas } & \multicolumn{2}{|c|}{ Nacional } & \multicolumn{2}{c|}{ Estrangeiro } & \multicolumn{2}{c}{ Total } \\
\cline { 2 - 7 } & Freqüência & $\%$ & Freqüência & $\%$ & Freqüência & $\%$ \\
\hline Existe & 15 & 46,9 & 13 & 61,9 & 28 & 52,8 \\
\hline Não Existe & 17 & 53,1 & 8 & 38,1 & 25 & 47,2 \\
\hline Total & 32 & 100,0 & 21 & 100,0 & 53 & 100,0 \\
\hline
\end{tabular}

Os dados apresentados nas Tabelas 3 a 6 , de uma forma geral, evidenciam que as empresas pesquisadas, no que se refere às práticas apresentadas, estão sincronizadas com as determinações consideradas como necessárias para o estabelecimento de um adequado sistema da qualidade, consistentes com as normas ISO e com os desenvolvimentos teóricos dos pesquisadores consultados.

\subsection{Quanto ao Planejamento e Controle dos Custos da Qualidade}

Na seqüência do estudo faz-se a análise e interpretação dos dados quanto aos procedimentos adotados pelas empresas no planejamento e controle dos custos da qualidade.

A primeira questão investigada relaciona-se com a emissão e análise dos relatórios que tratam dos custos da qualidade. Mais especificamente, ob- jetivou-se identificar qual o departamento encarregado de tal atividade.

Conforme dados da Tabela 7, não há, nas empresas nacionais, predominância de atuação da área financeira, representada pela contabilidade de custos e controladoria, que no conjunto participam com $28,2 \%$. O departamento de sistema da qualidade, por outro lado, responde por $50 \%$ das empresas pesquisadas. Nas empresas estrangeiras, ao contrário, verifica-se maior participação da contabilidade de custos e controladoria, com $57,2 \%$, contra $33,3 \%$ do departamento responsável pela gestão do sistema da qualidade. Analisando-se no total, nota-se a predominância desse último departamento, com $43,4 \%$ das empresas. Acrescente-se que, no global, $17 \%$ da amostra não faz mensuração dos custos da qualidade.

Note-se, aqui, a baixa adesão das empresas, principalmente das nacionais, às práticas recomendadas por Crosby (1994) e Feigenbaum (1994).

Tabela 7: Depto. Responsável pela Emissão e Análise de Relatórios dos Custos da Qualidade

\begin{tabular}{l|c|c|c|c|c|c}
\multirow{2}{*}{\multicolumn{1}{c}{ Departamento }} & \multicolumn{2}{c|}{ Nacional } & \multicolumn{2}{c}{ Estrangeiro } & \multicolumn{2}{c}{ Total } \\
\cline { 2 - 7 } & Freqüência & $\%$ & Freqüência & $\%$ & Freqüência & $\%$ \\
\hline Sistema da Qualidade & 16 & 50,0 & 7 & 33,3 & 23 & 43,4 \\
\hline Contabilidade de Custos & 3 & 9,4 & 6 & 28,6 & 9 & 17,0 \\
\hline Controladoria & 6 & 18,8 & 6 & 28,6 & 12 & 22,6 \\
\hline Não Utiliza & 7 & 21,9 & 2 & 9,5 & 9 & 17,0 \\
\hline Total & 32 & 100,0 & 21 & 100,0 & 53 & 100,0 \\
\hline
\end{tabular}


A classificação dos custos da qualidade quanto à sua natureza, se para qualidade ou da falta de qualidade, não é prática predominante nas empresas nacionais, identificando-se $28,1 \%$ para o primeiro caso e apenas $18,8 \%$ para o segundo. Mais relevante ainda é que $62,5 \%$ das nacionais não adotam tal separação, conforme consta da Tabela 8.
Já nas empresas estrangeiras, ainda que aquém do que recomendam os desenvolvimentos teóricos a respeito (CROSBY, 1994; FEIGENBAUM, 1994), verifica-se maior aderência a tal classificação, com $38,1 \%$ e $52,4 \%$ respectivamente. Ainda que em menor dimensão do que nas nacionais, nota-se aqui a elevada representatividade das em-

Tabela 8: Classificação dos Custos da Qualidade por Natureza

\begin{tabular}{l|c|c|c|c|c|c}
\multirow{2}{*}{ Natureza } & \multicolumn{3}{c|}{ Nacional } & \multicolumn{2}{c|}{ Estrangeiro } & \multicolumn{2}{c}{ Total } \\
\cline { 2 - 7 } & Freqüência & $\%$ & Freqüência & $\%$ & Freqüência & $\%$ \\
\hline Para Qualidade & 9 & 28,1 & 8 & 38,1 & 17 & 32,1 \\
\hline Da Falta de Qualidade & 6 & 18,8 & 11 & 52,4 & 17 & 32,1 \\
\hline Não Utiliza & 20 & 62,5 & 6 & 28,6 & 26 & 49,1 \\
\hline
\end{tabular}

presas que não adotam tal classificação, situandose em $28,6 \%$.

Quanto à classificação dos custos por categoria e conforme dados da Tabela 9, constata-se a maior adoção nas empresas estrangeiras da classificação ampla $(38,1 \%)$ em relação ao verificado nas nacionais $(31,3 \%)$. Tal adoção, também, se verifica na classificação entre os dois grupos principais, controle e falha, agora com diferença mais acentuada (19\% das estrangeiras contra $3,1 \%$ das nacionais). Conseqüentemente, comportamento inverso nota-se quando a classificação é somente pelo valor total $(19,0 \%$ contra 40,6\%). A não utilização das categorias de classificação não apresenta diferenças acentuadas entre os grupos de empresas, situando-se em torno de $25 \%$.

Os dados apresentados evidenciam que os procedimentos das empresas têm baixa consistência em relação ao prescrito por diversos autores consultados (Juran e Gryna, 1991; Crosby, 1994; Feigenbaum, 1994)

Tabela 9: Classificação dos Custos da Qualidade por Categoria

\begin{tabular}{l|c|c|c|c|c|c}
\multirow{2}{*}{\multicolumn{1}{c}{ Categoria }} & \multicolumn{2}{c|}{ Nacional } & \multicolumn{2}{c}{ Estrangeiro } & \multicolumn{2}{c}{ Total } \\
\cline { 2 - 7 } & Freqüência & $\%$ & Freqüência & $\%$ & Freqüência & $\%$ \\
\hline Prev/Aval/F.Int/F.Ext. & 10 & 31,3 & 8 & 38,1 & 18 & 34,0 \\
\hline Somente Controle e Falha & 1 & 3,1 & 4 & 19,0 & 5 & 9,4 \\
\hline Somente Valor Total & 13 & 40,6 & 4 & 19,0 & 17 & 32,1 \\
\hline Não Utiliza & 8 & 25,0 & 5 & 23,8 & 13 & 24,5 \\
\hline Total & 32 & 100,0 & 21 & 100,0 & 53 & 100,0 \\
\hline
\end{tabular}

A identificação explícita e isolada dos custos da qualidade nos relatórios gerenciais não é prática privilegiada nas empresas. Os dados da Tabela 10 evidenciam a preferência, de ambos os grupos de empresas, pela evidenciação dos custos de forma mais agregada, quer no resultado operacional, por unidade de negócios ou mesmo somente no consolidado.

Considerando-se os desenvolvimentos de Hansen e Mowen (2001) e Robles Jr. (2003), podese identificar que as empresas têm ainda muito a evoluir nesses procedimentos. 
Tabela 10: Formas de Apresentação dos Custos da Qualidade nos Relatórios de Resultado

\begin{tabular}{l|c|c|c|c|c|c}
\multirow{2}{*}{$\begin{array}{c}\text { Formas de } \\
\text { Apresentação }\end{array}$} & \multicolumn{2}{c|}{ Nacional } & \multicolumn{2}{c}{ Estrangeiro } & \multicolumn{2}{c}{ Total } \\
\cline { 2 - 7 } & Freqüência & $\%$ & Freqüência & $\%$ & Freqüência & $\%$ \\
\hline No Res.Op., Segregado & 2 & 6,3 & 1 & 4,8 & 3 & 5,7 \\
\hline No Res. Oper., Conjunto & 12 & 37,5 & 7 & 33,3 & 19 & 35,8 \\
\hline Somente Unid. Negócio & 8 & 25,0 & 8 & 38,1 & 16 & 30,2 \\
\hline Somente Consolidado & 5 & 15,6 & 4 & 19,0 & 9 & 17,0 \\
\hline Não Apresenta & 6 & 18,8 & 3 & 14,3 & 9 & 17,0 \\
\hline
\end{tabular}

Os dados da Tabela 11 evidenciam a utilização de parâmetros da representatividade dos custos da qualidade. Verifica-se acentuada não mensuração de tal representatividade, sendo $84,4 \%$ das empresas nacionais e $66,7 \%$ das estrangeiras. Quando utilizado, prevalece a receita líquida como parâmetro mais utilizado. Também, aqui, nota-se a baixa adesão às práticas recomendadas por Feigenbaum (1994), Juran e Gryna, (1991) e Robles Jr. (2003).

Tabela 11: Parâmetro para Mensuração Percentual do Custo da Qualidade

\begin{tabular}{l|c|c|c|c|c|c}
\multirow{2}{*}{\multicolumn{1}{c}{ Parâmetro }} & \multicolumn{3}{c|}{ Nacional } & \multicolumn{2}{c}{ Estrangeiro } & \multicolumn{2}{c}{ Total } \\
\cline { 2 - 7 } & Freqüência & $\%$ & Freqüência & $\%$ & Freqüência & $\%$ \\
\hline Custo Total & 2 & 6,3 & 3 & 14,3 & 5 & 9,4 \\
\hline Receita Líquida & 3 & 9,4 & 4 & 19,0 & 7 & 13,2 \\
\hline Outros Parâmetros & 0 & 0,0 & 0 & 0,0 & 0 & 0,0 \\
\hline Não Mensura & 27 & 84,4 & 14 & 66,7 & 41 & 77,4 \\
\hline Total & 32 & 100,0 & 21 & 100,0 & 53 & 100,0 \\
\hline
\end{tabular}

A adoção de um plano orçamentário dos custos da qualidade pelas empresas, conforme dados da Tabela 12, ainda carece de melhora sendo, ainda assim, mais bem desenvolvido nas empresas estrangeiras. Enquanto nelas o uso de apenas uma estimativa, ou mesmo a não utilização, representa
$33,3 \%$, nas nacionais essa representatividade elevase a $53,2 \%$. A classificação mais adequada, custo para obter e custo da falta, semelhante a custo para controle e custo de falhas, é adotada por $33,3 \%$ das estrangeiras contra apenas $18,8 \%$ das nacionais.

Tabela 12: Orçamento e Classificação dos Custos da Qualidade

\begin{tabular}{l|c|c|c|c|c|c}
\hline \multirow{2}{*}{$\begin{array}{c}\text { Tipos de Orçamento } \\
\text { e Classificação }\end{array}$} & \multicolumn{2}{|c|}{ Nacional } & \multicolumn{2}{c}{ Estrangeiro } & \multicolumn{3}{c}{ Total } \\
\cline { 2 - 7 } & Freqüência & $\%$ & Freqüência & $\%$ & Freqüência & \% \\
\hline Orç.p/obter e da Falta & 6 & 18,8 & 7 & 33,3 & 13 & 24,5 \\
\hline Orçamento Valor Total & 9 & 28,1 & 7 & 33,3 & 16 & 30,2 \\
\hline Há apenas Estimativa & 6 & 18,8 & 2 & 9,5 & 8 & 15,1 \\
\hline Não há orçamento & 11 & 34,4 & 5 & 23,8 & 16 & 30,2 \\
\hline Total & 32 & 100,0 & 21 & 100,0 & 53 & 100,0 \\
\hline
\end{tabular}

A existência de um procedimento formal de análise do custo real em relação ao orçado também é prática mais acentuadamente adotada pelas empresas estrangeiras ante as nacionais $(57,1 \%$ contra 46,9\%). O mesmo ocorre quanto à análise em relação ao histórico $(23,8 \%$ contra $9,4 \%)$. Por outro lado, a não avaliação do nível de alcance das metas orçadas é prática mais dominante nas em- 
presas nacionais $(40,6 \%$ contra $19,0 \%)$, conforme Tabela 13.

Sakurai (1997), ao defender a utilidade de um plano orçamentário para os custos da qualidade, enfatiza que, quando a empresa deseja estabelecer uma meta efetiva para controlar a atividade gerencial, os custos de prevenção e avaliação são boas metas orçamentárias. Nesse sentido, nota-se que as empresas pesquisadas têm, ainda, muito que evoluir.

Tabela 13: Análise Real x Orçado dos Custos da Qualidade

\begin{tabular}{l|c|c|c|c|c|c}
\multirow{2}{*}{ Formas de Análise } & \multicolumn{2}{|c|}{ Nacional } & \multicolumn{2}{c}{ Estrangeiro } & \multicolumn{3}{c}{ Total } \\
\cline { 2 - 7 } & Freqüência & $\%$ & Freqüência & $\%$ & Freqüência & $\%$ \\
\hline Há Análise Formal & 15 & 46,9 & 12 & 57,1 & 27 & 50,9 \\
\hline Há Análise c/Histórico & 3 & 9,4 & 5 & 23,8 & 8 & 15,1 \\
\hline Outros & 1 & 3,1 & 0 & 0,0 & 1 & 1,9 \\
\hline Não Analisa & 13 & 40,6 & 4 & 19,0 & 17 & 32,1 \\
\hline Total & 32 & 100,0 & 21 & 100,0 & 53 & 100,0 \\
\hline
\end{tabular}

Partindo-se da premissa de que sob o enfoque da gestão de capitais as inversões em sistemas da qualidade revestem-se da figura de um investimento que, para sua justificativa, deve propiciar alguma forma de retorno, essa parte final de coleta de dados da pesquisa concentrou-se na identificação sobre a forma de controle dos investimentos. Os dados da Tabela 14 evidenciam que parcela substancial das empresas $(56,3 \%$ das nacionais contra $47,6 \%$ das estrangeiras) não possui controles específicos para os investimentos realizados.

Obviamente, tal procedimento prejudica a aplicação de indicadores direcionados à mensuração dos retornos obtidos. Isso fica evidente nos dados apresentados na Tabela 15, constatando-se que $87,5 \%$ das empresas nacionais e $81 \%$ das estrangeiras (equivalente a $84,9 \%$ no total) não mensuram os retornos obtidos com os investimentos realizados.

Tabela 14: Controle do Investimento no Sistema de Gestão da Qualidade

\begin{tabular}{l|c|c|c|c|c|c}
\hline \multirow{2}{*}{$\begin{array}{c}\text { Controle do Investim. } \\
\text { em Separado }\end{array}$} & \multicolumn{2}{|c|}{ Nacional } & \multicolumn{2}{c|}{ Estrangeiro } & \multicolumn{3}{c}{ Total } \\
\cline { 2 - 7 } & Freqüência & $\%$ & Freqüência & $\%$ & Freqüência & $\%$ \\
\hline Existe & 14 & 43,8 & 11 & 52,4 & 25 & 47,2 \\
\hline Não Existe & 18 & 56,3 & 10 & 47,6 & 28 & 52,8 \\
\hline Total & 32 & 100,0 & 21 & 100,0 & 53 & 100,0 \\
\hline
\end{tabular}

Tabela 15: Mensuração do Retorno do Investimento no Sistema de Gestão da Qualidade

\begin{tabular}{|c|c|c|c|c|c|c|}
\hline \multirow{2}{*}{$\begin{array}{l}\text { Retorno do } \\
\text { Investimento }\end{array}$} & \multicolumn{2}{|c|}{ Nacional } & \multicolumn{2}{|c|}{ Estrangeiro } & \multicolumn{2}{|c|}{ Total } \\
\hline & Freqüência & $\%$ & Freqüência & $\%$ & Freqüência & $\%$ \\
\hline Existe & 4 & 12,5 & 4 & 19,0 & 8 & 15,1 \\
\hline Não Existe & 28 & 87,5 & 17 & 81,0 & 45 & 84,9 \\
\hline Total & 32 & 100,0 & 21 & 100,0 & 53 & 100,0 \\
\hline
\end{tabular}

\section{CONCLUSÕES}

Esta pesquisa, realizada com empresas de significativa relevância econômica, possibilitou eviden- ciar sua baixa adesão à implantação de um formal sistema de planejamento e controle dos custos da qualidade, embora haja farta literatura abordando a sua necessidade e utilidades. Os dados coletados 
permitem identificar que nem mesmo a emissão da norma NBR ISO 9004:2000 provocou mudanças relevantes nesse posicionamento.

A comparação dos resultados deste estudo com aqueles apresentados por Mattos e Toledo (1998) e Moori e Silva (2001) atestam tal afirmativa. Mesmo no contexto internacional, já em 1987 situação semelhante foi identificada, conforme estudo de Sakurai (1997). Além dele, Tatikonda e Tatikonda (1996), também, enfatizam que somente umas poucas companhias mensuram seus custos da qualidade e, quando o fazem, eles são grosseiramente subavaliados.

Algumas constatações específicas são suficientes para resumir o estágio em que se encontram tais trabalhos nas empresas pesquisadas: [1] 49,1\% das empresas $(62,5 \%$ das nacionais e $28,6 \%$ das estrangeiras) não segregam os custos entre "para" e "da falta" da qualidade; [2] 56,6\% das empresas (65,6\% das nacionais e $42,8 \%$ das estrangeiras) não adotam a classificação desenvolvida por Feigenbaum e referendada por diversos pesquisadores; [3] somente $5,7 \%$ das empresas adotam relatórios segregando os custos da qualidade em seu resultado operacional; [4] $77,4 \%$ das empresas $(84,4 \%$ das nacionais e $66,7 \%$ das estrangeiras) não utilizam um parâmetro para dimensionar a representatividade percentual dos custos da qualidade; [5] $45,3 \%$ das empresas $(53,2 \%$ das nacionais e $33,3 \%$ das estrangeiras) não fazem orçamento formal dos custos da qualidade ou utilizam-se apenas de uma estimativa; [6] 52,8\% das empresas (56,3\% das nacionais e $47,6 \%$ das estrangeiras) não têm controle específicos dos investimentos do sistema da qualidade; [7] $84,9 \%$ das empresas $(87,5 \%$ das nacionais e $81,0 \%$ das estrangeiras) não mensuram o retorno dos investimentos da qualidade e [8] somente em $39,6 \%$ das empresas $(28,2 \%$ das nacionais e $57,2 \%$ das estrangeiras) há a efetiva participação da controladoria ou contabilidade de custos na emissão de relatórios de custos da qualidade.

Note-se que as empresas estrangeiras, ainda que distantes do prescrito pela literatura, adotam com maior intensidade as práticas de mensuração e controle dos custos da qualidade do que as nacionais. Tal posicionamento pode ser decorrente de uma cultura organizacional baseada na adoção de um modelo de gestão que adote com maior ênfase a filosofia do planejamento e controle das atividades. Pesquisa específica nesse sentido poderá trazer luz a essa questão.

Com base em tais indicadores é possível concluir que parcela significativa dessas empresas está muito mais próxima do entendimento de Deming (de que não há necessidade de mensurar e controlar os custos da qualidade) do que de Crosby (de que a necessidade existe).

Também é possível inferir que não há reconhecimento por parte das empresas pesquisadas para o fato de que a certificação dos sistemas de gestão da qualidade, por si só, não é suficiente para assegurar o sucesso econômico-financeiro. O mesmo ocorre com relação ao entendimento de que a adoção isolada de medidas não financeiras, apesar de mais fácil de serem mensuradas, isoladamente não identifica o quanto a qualidade não atendida pode ser cara. Nesse sentido, é necessário incorporar o entendimento de que as medidas financeiras, na figura de um denominador comum, correspondem a uma medida concisa do desempenho da qualidade.

Durante a realização deste estudo constatouse que há, ainda, uma ampla agenda de estudos a serem realizados sobre os custos da qualidade. Dentre eles, citam-se os seguintes: a) investigar junto às empresas a causa central da não adoção dos procedimentos prescritos na literatura; $b$ ) investigar se as empresas têm conhecimento real das perdas financeiras provocadas pela falta da qualidade; c) investigar junto às empresas certificadoras sobre como elas se posicionam diante da omissão constatada à luz da norma NBR ISO 9004:2000; d) investigar como os controllers das empresas, os quais têm como missão subsidiar que as melhores decisões sejam privilegiadas e assim assegurar o alcance da eficácia das organizações, posicionam-se a respeito.

Acredita-se que o desenvolvimento dessas pesquisas, dentre outras que possam ser identificadas, muito contribuirão para o aperfeiçoamento global e sistêmico dos sistemas de gestão da qualidade. 


\section{REFERÊNCIAS BIBLIOGRÁFICAS}

ANDRADE, Fábio F.. O Método de melhorias PDCA. 2003. Dissertação de Mestrado apresentada à Escola Politécnica da Universidade de São Paulo, São Paulo.

ATKINSON, Anthony A.; BANKER, Rajiv D.; KAPLAN, Robert S.; YOUNG, S. Mark. Contabilidade gerencial. São Paulo: Atlas, 2000.

CARVALHO, João B. C.; LOBO, Carla S. P.; AGUIAR, Sérgio R.; CALADO, Lara. A qualidade total: necessidade de rever os sistemas de custos tradicionais. VII Congresso Brasileiro de Custos, Recife, 2000.

CASTRO, Marcelo L.. Uma contribuição ao estudo da harmonização das normas contábeis na era da globalização. $1^{\circ}$ Seminário USP de Contabilidade. São Paulo, USP, out. 2001.

CONSELHOFEDERALDE CONTABILIDADE(CFC). Harmonização de normas contábeis: um estudo sobre as divergências entre normas contábeis internacionais e seus reflexos na contabilidade brasileira. Disponível em www.cfc.org.br/uparq/trab4colocado. pdf. Acesso em 15.Mar.2005.

CROSBY, Philip B.. Qualidade é investimento. Rio de Janeiro: José Olympio, 1994.

DEMING, Willian E.. Qualidade: a revolução da administração. Rio de Janeiro: Marques-Saraiva, 1990.

FAWCETT, Stanley E.; CALANTONE, Roger J.; ROATH, Anthony. Meeting quality and cost imperatives in a global market. Bradford, International Journal of Physical Distribution \& Logistics Management, 2000, v. 30, p. 472.

FEIGENBAUM, Armand V.. Controle da qualidade total. São Paulo: Makron Books, 1994.

FUNDAÇÃO PARA O PRÊMIO NACIONAL DA QUALIDADE - FPNQ. Cadastro de associados. Disponível em: <www.fpnq. org.br>. Acesso em 26.ago.2004.

GARRISON, Ray H.; NOREEN, Eric W.. Contabilidade gerencial. Rio de Janeiro: LTC, 2001.

GIL, Antonio C.. Métodos e técnicas de pesquisa social. São Paulo: Atlas, 1999.

HANSEN, Don R.; MOWEN, Maryanne M.. Gestão de custos: contabilidade e controle. São Paulo: Pioneira Thomson Learning, 2001

HORNGREN, Charles T.; FOSTER, George; DATAR, Srikant M.. Contabilidade de custos. Rio de Janeiro: LTC, 2000.

IMBERMAN, Woodruff. Eliminating the cost of poor quality. FDM Des Plaines, Oct. 2001, p. 100-103.

ISHIKAWA, K.. Controle de qualidade total à maneira japonesa. Rio de Janeiro: Campus, 1998.

IUDíCIBUS, Sérgio. A Gestão estratégica de custos e sua interface com a contabilidade gerencial e a teoria da contabilidade.
Brasília, Revista Brasileira de Contabilidade, $\mathrm{n}^{\circ}$ 100, jul/ago., p.30-31, 1996.

JURAN, J.M.; GRYNA, Frank M.. Controle da qualidade. São Paulo: McGraw-Hill, 1991.

LAKATOS, Eva M.; MARCONI, Marina A.. Fundamentos de metodologia científica. São Paulo: Atlas, 1991.

LIMA, Sandro A.; MARTINS, Manoel F.. Custos da qualidade na indústria de calçados de couro. VIII Congresso Brasileiro de Custos, São Leopoldo, 2001.

MAHER, Michael. Contabilidade de custos. São Paulo: Atlas, 2001.

MATTOS, Jarbas C.; TOLEDO, José C.. Custos da qualidade: diagnóstico nas empresas com certificação ISSO 9000. Gestão e Produção, v.5, n.3, p.312-324, dez. 1998.

MONDEN, Yasuhiro. Sistemas de redução de custos. Porto Alegre; Bookman, 1999.

MOORI, Roberto G.; SILVA, Rubens V.. Um Estudo do sistema de gestão do Custo da qualidade nas empresas químicas do Brasil. XXV EnANPAD, Campinas, 2001.

NAKAGAWA, Masayuki. Gestão estratégica de custos: conceitos, sistemas e implementação. São Paulo: Atlas, 1991.

NASCIMENTO, Jeferson S.. Gerenciamento estratégico de custos da qualidade. VIII Congresso del Instituto Internacional de Costos, Punta del Este, 2003.

NBR ISO 9001 - Sistema de Gestão da qualidade: requisitos. Rio de Janeiro: ABNT, 2000.

NBR ISO 9004 - Sistema de Gestão da qualidade: diretrizes para melhorias de desempenho. Rio de Janeiro: ABNT, 2000.

OAKLAND, John. Gerenciamento da qualidade total. São Paulo: Nobel, 1994.

OLIVEIRA, Otávio J.; MELHADO, Sílvio B.. Nova norma ISO 9000 Versão 2000. In: OLIVEIRA, Otávio J. (org), Gestão da qualidade: tópicos avançados. São Paulo: Pioneira Thomson Learning, 2004, p. 57-75.

OSADA, Takashi. Housekeeping, 5S's: Seiri, Seiton, Seiso, Seiketsu, Shitsuke. São Paulo: IMAN, 1992.

PORTER, Michael E.. Vantagem competitiva: criando e sustentando um desempenho superior. Rio de Janeiro: Campus, 1990.

QUESADO, Patrícia R.; DA COSTA, Teresa C. S.. Os custos da qualidade: estudo de casos de empresas portuguesas. IX Congresso Internacional de Custos, Itapema, 2005.

ROBLES JR., Antonio. Custos da Qualidade: aspectos econômicos da gestão da qualidade e da gestão ambiental. São Paulo: Atlas, 2003. 
RUST, Roland T.; ZAHORIK, Anthony J.; KEININGHAM, Timothy L.. Return on quality: measuring the financial impact of your company's quest for quality. Chicago: Irwin, 1994.

SACCO GALLORO, Lídia Rosa R.; STEPHANI, Douglas E.. Custos da qualidade e da não-qualidade. In: Custo como ferramenta gerencial. Conselho Regional de Contabilidade do Estado de São Paulo. São Paulo: Atlas, 1995.

SAKURAI, Michiharu. Gerenciamento integrado de custos. São Paulo: Atlas, 1997.
SHANK, John K.; GOVINDARAJAN, Vijay. A Revolução dos custos. Rio de Janeiro: Campus, 1997.

TATIKONDA, Lakshmi U.; TATIKONDA, Rao J.. Measuring and reporting the cost of quality. Production and Inventory Management Journal. Second Quarter 1996, vol. 37, Iss. 2; p. 1-7.

WILBUR, Jay H.. Is Time running out for quality? Milwaukee: Quality Progress, Jul. 2002, p. 75-79.

\section{Endereço dos autores:}




\section{Apêndice: QUESTIONÁRIO DE PESQUISA SOBRE CUSTOS DA QUALIDADE}

\begin{tabular}{|c|c|}
\hline \multicolumn{2}{|c|}{ I - IDENTIFICAÇÃO DA EMPRESA } \\
\hline \multicolumn{2}{|l|}{ Razão Social: } \\
\hline \multicolumn{2}{|l|}{ Atividade: } \\
\hline \multicolumn{2}{|l|}{ Localização (Cidade e Estado): País de Origem: } \\
\hline \multicolumn{2}{|l|}{ Respondente: } \\
\hline \multicolumn{2}{|l|}{ Cargo do Respondente: Telef. e E-mail: } \\
\hline Fat $^{\circ}$ Anual em milhões de US\$ (marcar " $\left.x "\right)$ & Número de Funcionários -(marcar “ $x$ ”) \\
\hline Até 30 & Até 500 \\
\hline De 31 a 50 & De 501 a 750 \\
\hline De 51 a 100 & De 751 a 1.000 \\
\hline De 101 a 150 & De 1.001 a 2.000 \\
\hline De 151 a 200 & De 2.001 a 3.000 \\
\hline De 201 a 300 & De 3.001 a 5.000 \\
\hline Acima de 300 & Acima de 5.000 \\
\hline \multicolumn{2}{|c|}{ II - QUESTÕES PESQUISADAS } \\
\hline \multicolumn{2}{|c|}{ 1. Credenciamento do Sistema da Qualidade } \\
\hline \multicolumn{2}{|l|}{ Nome da Entidade Auditora: } \\
\hline \multicolumn{2}{|l|}{ Nome da Entidade de Acreditação: } \\
\hline \multicolumn{2}{|l|}{ Norma(s) Credenciada(s): } \\
\hline \multicolumn{2}{|l|}{ Mês e Ano do Credenciamento: } \\
\hline \multicolumn{2}{|c|}{ 2. Ferramentas/Programas de Gestão da Qualidade Adotadas (assinalar com " $x ")$} \\
\hline \multicolumn{2}{|c|}{ PDCA } \\
\hline \multicolumn{2}{|l|}{ Seis Sigmas } \\
\hline \multicolumn{2}{|l|}{ Outras (Especificar): } \\
\hline \multicolumn{2}{|c|}{ 3. Estrutura Organizacional do Sistema da Qualidade (assinalar sim ou não) } \\
\hline \multicolumn{2}{|c|}{ A empresa possui área especificamente responsável pelo sistema da qualidade? } \\
\hline \multicolumn{2}{|c|}{ 4. Nível hierárquico do(s) responsável(is) pelo Sistema (assinalar com " $x$ ") } \\
\hline \multicolumn{2}{|l|}{ Diretor } \\
\hline \multicolumn{2}{|l|}{ Gerente } \\
\hline \multicolumn{2}{|l|}{ Supervisor } \\
\hline Outros (especificar): & \\
\hline 5. Recompensas a Funcionários (assinalar sim ou $\mathrm{n}$ & \\
\hline Existe algum sistema de estímulo (premiação, grat & cance dos níveis de custos e de qualidade estabelecidos? \\
\hline 6. Tipo de Informação nos Relatórios de Custos da & lar com "x") \\
\hline Informação expressa em medidas físicas & \\
\hline Informação expressa em medidas monetárias & \\
\hline Informação expressa em medidas físicas e mor & \\
\hline Outros (especificar): & \\
\hline 7. Itens Considerados na Mensuração do Processo & inalar com “ $x ")$ \\
\hline Depreciação dos Equipamentos Utilizados & \\
\hline Materiais Indiretos Diversos & \\
\hline Matéria Prima & \\
\hline Horas de Máquinas Utilizadas & \\
\hline Horas de Mão de Obra Direta & \\
\hline Horas de Mão de Obra Indireta & \\
\hline Manutenção de Equipamentos & \\
\hline Gastos com Sistema da Qualidade (treinament & \\
\hline Energia Elétrica e/ou Combustíveis & \\
\hline
\end{tabular}




\begin{tabular}{|c|c|}
\hline & Outros (especificar): \\
\hline & Outros (especificar): \\
\hline \multicolumn{2}{|r|}{ 8. Identificação da Natureza dos Custos da Qualidade (assinalar com " $x$ ”) } \\
\hline & Adota-se a Classificação de Custos PARA obtenção da Qualidade \\
\hline & Adota-se a Classificação de Custos da FALTA de Qualidade \\
\hline & Não é Adotada essa Classificação \\
\hline \multicolumn{2}{|r|}{ 9. Investimento e Retorno do Sistema da Qualidade (assinalar sim ou não) } \\
\hline & $\begin{array}{l}\text { O Valor ref. aos Investimentos em Qualidade (estação de tratamento de efluentes, veículos e equipamentos exclusivos, } \\
\text { treinamento, implantação do sistema da qualidade, processo de legalização CETESB, etc) são Controlados Separada- } \\
\text { mente? }\end{array}$ \\
\hline & É Mensurado o Retorno sobre o Investimento do Sistema? Se SIM, Qual a Medida de Retorno Utilizada (especificar): \\
\hline \multicolumn{2}{|r|}{ 10. Dimensão Percentual do Custo da Qualidade (assinalar com a \% correspondente) } \\
\hline & Em Relação ao Custo Total de Produção \\
\hline & Em Relação à Receita Líquida \\
\hline & Outra Base de Relação (especificar qual): \\
\hline & Não é Feita Nenhuma Relação \\
\hline \multicolumn{2}{|r|}{ 11. Classificação Adotada no Registro dos Custos da Qualidade (assinalar com " $x$ ") } \\
\hline & Detalhamento Total (Prevenção, Avaliação, Falha Interna, Falha Externa) \\
\hline & Detalhamento Parcial (Controle e Falhas) \\
\hline & Somente pelo Valor Total \\
\hline & Outra (especificar): \\
\hline \multicolumn{2}{|r|}{ 12. Depto. Responsável pela Emissão e Análise de Relatórios (assinalar com " $x$ ") } \\
\hline & Pelo Próprio Departamento Envolvido \\
\hline & Pela Contabilidade de Custos \\
\hline & Pela Controladoria \\
\hline & Outro (especificar): \\
\hline \multicolumn{2}{|r|}{ 13. Apresentação dos Custos da Qualidade (assinalar com " $x$ ”) } \\
\hline & No Resultado Operacional, Segregado dos Demais Custos \\
\hline & No Resultado Operacional, Juntamente com os Demais Custos \\
\hline & Por Divisão / Unidade de Negócios \\
\hline & Somente no Resultado Consolidado \\
\hline & Outra Forma (especificar): \\
\hline \multicolumn{2}{|r|}{ 14. Orçamento (Budget) e Classificação dos Custos da Qualidade (assinalar com "x") } \\
\hline & Há Previsão Orçamentária Formal Segregada em "Para Obter" e da "Falta" da Qualidade \\
\hline & Há Previsão Orçamentária Somente Pelo Valor Total \\
\hline & Há Previsão Orçamentária Informal (Apenas estimativa) \\
\hline & Outra Forma (especificar): (Mista: Alguns dados são segregados e outros não) \\
\hline & Não Há Previsão Orçamentária \\
\hline \multicolumn{2}{|r|}{ 15. Qual a Métrica (indicador) de Falta de Qualidade Utilizada (assinalar com “x") } \\
\hline & Perda por Milhão (PPM) \\
\hline & Índice (\%) de Defeitos em Relação à Produção Total \\
\hline & Garantia Executada (devolução de produtos, substituição de produtos, consertos etc) \\
\hline & Retrabalho de Defeitos Identificados Durante o Processo Produtivo \\
\hline & Outros (especificar): \\
\hline \multicolumn{2}{|r|}{ 16. Análise do Desempenho Real dos Custos da Qualidade (assinalar com " $x$ ") } \\
\hline & Há Avaliação Formal do Real x Orçado \\
\hline & Há Avaliação Somente em Relação ao Histórico \\
\hline & Outra Forma (especificar): \\
\hline & Não Há Avaliação \\
\hline
\end{tabular}

